\title{
Prediction of growth kinetics of Pseudomonas spp. in meat products under isothermal and non-isothermal storage conditions
}

\section{Fatih TARLAK}

Cite this article as:

Tarlak, F. (2021). Prediction of growth kinetics of Pseudomonas spp. in meat products under isothermal and non-isothermal storage conditions. Food and Health, 7(3), 194-202. https://doi.org/10.3153/FH21021

Istanbul Gedik University, Department of Nutrition and Dietetics, 34876,

Kartal, Istanbul, Turkey

ORCID IDs of the authors:

F.T. 0000-0001-5351-1865

Submitted: 07.01 .2021

Revision requested: 26.01 .2021

Last revision received: 11.02 .2021

Accepted: 12.02 .2021

Published online: 13.05 .2021

Correspondence:

Fatih TARLAK

E-mail: ftarlak@gtu.edu.tr

\section{ABSTRACT}

The main objective of the present study was to develop and validate a new alternative modelling method to predict the shelf-life of food products under non-isothermal storage conditions. The bacterial growth data of the Pseudomonas spp. was extracted from published studies conducted for aerobically-stored fish, pork and chicken meat and described with two-step and one-step modelling approaches employing different primary models (the modified Gompertz, logistic, Baranyi and Huang models) under isothermal storage temperatures. Temperature dependent kinetic parameters (maximum specific growth rate ' $\mu_{\max }$ ' and lag phase duration ' $\lambda$ ') were described as a function of storage temperature via the Ratkowsky model integrated with each primary model. The Huang model based on the one-step modelling approach yielded the best goodness of fit results (RMSE $=0.451$ and adjusted- $\mathrm{R}^{2}=0.942$ ) for all food products at isothermal storage conditions, therefore, was also used to check it's the prediction capability under non-isothermal storage conditions. The differential form of the Huang model provided satisfactorily statistical indexes $\left(1.075>\mathrm{B}_{\mathrm{f}}>1.014\right.$ and $1.080>\mathrm{A}_{\mathrm{f}}>1.047$ ) indicating reliably being able to use to describe the growth behaviour of Pseudomonas spp. in fish, pork and chicken meat subjected to non-isothermal storage conditions.

Keywords: Dynamic condition, Microbiological quality, Pseudomonas spp., growth kinetic, Predictive microbiology

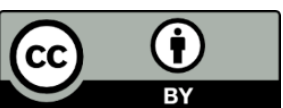

(c) 2021 The Author(s)

Available online at http://jfhs.scientificwebjournals.com 


\section{Introduction}

Meat is among nutrient-dense foods and is a source of protein. Fish, pork and chicken meat play an important role in meat industry; however, are highly perishable food products even when kept under refrigeration, which may result in an important economic loss (Bruckner et al., 2013; Dominguez and Schaffner, 2007; Koutsoumanis, 2001). Initial microbial quality and storage conditions have a direct effect on product shelf-life, and Pseudomonas spp. is one of the most abundant bacterial genera, naturally existing in fish, pork and chicken microbiota (Bruckner et al., 2013; GhollasiMood et al., 2017; Lytou et al., 2016; Koutsoumanis, 2001).

Microbial load in food can be determined with traditional microbiological enumeration techniques. Even more, the results of these techniques give us only information about specific time and condition. But the growth behaviour of microorganisms depends on changing environmental factors. Therefore, the traditional enumeration techniques are not adequately practical. Predictive microbiology is a tool used to describe microbial behaviour in food. Although traditional microbiological methods have high costs and time-consuming results, these methods are still used simultaneously with predictive microbiology to describe microbial behaviour in the development of products and processes (Bovill et al., 2001).

The main objective of predictive microbiology is to predict microbial behaviour, which can prevent food spoilage as well as food-borne illnesses by employing mathematical models. Primary and secondary models are commonly used in predictive food microbiology (Whiting, 1995). For the primary models, the modified Gompertz, logistic, Baranyi and Huang models are the most popular ones describing microbial growth data as a function of time at constant environmental conditions. The secondary models indicate how obtained the growth parameters from primary models change with respect to one or more environmental or cultural factors (e.g., gas composition, $\mathrm{pH}$, temperature and salt level). Temperature is one of the most important environmental factors directly affecting the growth behaviour of microorganisms in foods, and its effect is widely described using the Ratkowsky model (Ratkowsky et al., 1982).

Under real life conditions, environmental factors are not always constant during the pass time for the food product reaches consumers (Zwietering et al., 1994). Therefore, dynamic models are essential to model by taking into account the changing environmental conditions which a food product really subjects to (Pérez-Rodríguez and Valero, 2013). Dynamic models considering the effect of changing temperature are important to model the effect of the temperature on microbial growth under non-isothermal conditions.

Generally, the primary and secondary models are separately fitted to the growth data and kinetic parameters, respectively and this is the most popular modelling procedure followed in the predictive food microbiology. But there are some drawbacks concerning about this modelling approach. The major drawback is to lead to be accumulation and propagation of errors due to being sequentially performed nonlinear regression two times (Huang, 2017). To avoid these disadvantages of two-step modelling approach, alternatively, a one-step modelling approach can be applied while simulating microbial data and kinetic parameters. In this approach, primary and secondary modelling for the growth and temperature (as a changing environmental factor) data is performed simultaneously. Therefore, the use of this approach frequently provides better prediction performance, lower uncertainty, more precise coefficients and robust confidence interval than the two-step modelling approach (Jewell, 2012; Martino and Marks, 2007).

In the present study, the growth behaviour of Pseudomonas spp. naturally existing in fish, pork and chicken microbiota were described with both two-step and one-step modelling approaches for isothermal storage conditions. The fitting capabilities of both approaches were compared and the approach which gave better fitting performance was tested under non-isothermal storage conditions.

\section{Materials and Methods}

\section{Experimental Data}

The bacterial growth data of Pseudomonas spp. were extracted from the published works performed for fish, pork and chicken meat (Bruckner, 2010; Bruckner et al., 2013; Koutsoumanis, 2001). While there were six isothermal storage conditions $\left(0,2,5,8,10\right.$ and $\left.15{ }^{\circ} \mathrm{C}\right)$ to simulate the bacterial growth behaviour for fish (Koutsoumanis, 2001), there were five isothermal storage conditions $\left(2,4,7,10\right.$ and $\left.15^{\circ} \mathrm{C}\right)$ for pork and chicken meat (Bruckner, 2010; Bruckner et al., 2013). The experimental set-ups to monitor Pseudomonas spp. in the targeted food products (fish, pork and chicken meat) were explained in detail in the respective studies (Bruckner, 2010; Bruckner et al., 2013; Koutsoumanis, 2001). In brief, food products were transported to the laboratory under temperature-controlled refrigeration conditions. As soon as they arrived and the initial microbiological analyses of them were performed, and they were started to keep at aerobically storage conditions. For microbiological analyses, food samples $(25 \mathrm{~g})$ were added aseptically to $225 \mathrm{~mL}$ 
of $0.1 \%$ peptone water with salt $(\mathrm{NaCl}, 0.85 \%)$, and the mixture was homogenized for $60 \mathrm{~s}$ with a stomacher. A 10-fold dilution series of the homogenate was prepared using saline peptone diluents. Appropriate dilutions were transferred to Pseudomonas Agar Base with CFC supplement (Oxoid) incubating at $20-25^{\circ} \mathrm{C}$ for $48 \mathrm{~h}$. In the current study, data collection process for the growth curves was performed using GetData Graph Digitizer 2.26 software (www.getdata-graphdigitizer.com) by which the growth data points could be extracted accurately with one decimal precision.

\section{Modelling}

Four different primary models namely the modified Gompertz (Zwietering et al., 1990), logistic (Zwietering et al., 1990), Baranyi (Baranyi and Roberts, 1994) and Huang (Huang 2017) models were fitted with the two-step and onestep modelling approaches as they are the most used sigmoid functions that describe the bacterial growth behaviour and are defined by Eqs (1), (2), (3) and (4), respectively at constant environmental conditions:

$y(t)=y_{0}+\left(y_{\max }-y_{0}\right) \cdot \exp \left\{-\exp \left[\frac{\mu_{\max } \cdot e}{\left(y_{\max }-y_{0}\right)} \cdot(\lambda-t)+1\right]\right\}(1)$

$y(t)=y_{0}+\frac{\left(y_{\max }-y_{0}\right)}{\left\{1+\exp \left[\frac{4 . \mu_{\max }}{\left(\mathrm{y}_{\max }-y_{0}\right)} \cdot(\lambda-t)+2\right]\right\}}$

$y(t)=y_{0}+\mu_{\max } F(t)-\ln \left(1+\frac{e^{\mu_{\max } F(t)}-1}{e^{\left(y_{\max }-y_{0}\right)}}\right)$

$y(t)=y_{0}+y_{\max }-\ln \left(e^{y_{0}}+\left[e^{y_{\max }}-e^{y_{0}}\right] \cdot e^{-\mu_{\max } B(t)}\right)$

$F(\mathrm{t})$ and $B(\mathrm{t})$ are the adjustment functions that are respectively described by Baranyi and Roberts (1994) and Huang (2017):

$$
\begin{array}{r}
\mathrm{F}(\mathrm{t})=\mathrm{t}+\frac{1}{\mathrm{v}} \ln \left(\mathrm{e}^{-\mathrm{vt}}+\mathrm{e}^{-\mu_{\max } \lambda}\right. \\
\left.-\mathrm{e}^{\left(-\mathrm{vt}-\mu_{\max } \lambda\right)}\right) \\
\mathrm{B}(\mathrm{t})=\mathrm{t}+\frac{1}{4} \ln \left(\frac{1+\mathrm{e}^{-4(\mathrm{t}-\lambda)}}{1+\mathrm{e}^{4 \lambda}}\right)
\end{array}
$$

where $\mathrm{t}$ is the time (h), $y(t)$ is the concentration of bacterial populations (ln $\mathrm{CFU} / \mathrm{g}$ ) at time $\mathrm{t}, y_{0}$ is the initial concentration of bacterial populations ( $\ln \mathrm{CFU} / \mathrm{g}), y_{\max }$ is the maximum concentration of bacterial populations ( $\ln \mathrm{CFU} / \mathrm{g}$ ), $\mu_{\max }$ is the maximum specific bacterial growth rate $(1 / \mathrm{h}), \lambda$ is the duration of lag phase (h) and $v$ is the rate of increase of limiting substrate, assumed to be equal to $\mu_{\max }$.

The Ratkowsky model (Ratkowsky et al., 1982) was employed for the determination of relationship between storage temperature and $\mu_{\max }$ using the Eq. (7):

$$
\sqrt{\mu_{\max }}=\mathrm{b}_{1}\left(\mathrm{~T}-\mathrm{T}_{0}\right)
$$

where $T$ is the storage temperature $\left({ }^{\circ} \mathrm{C}\right), T_{0}$ is the notional temperature $\left({ }^{\circ} \mathrm{C}\right), \mu_{\max }$ is the maximum specific bacterial growth rate $(1 / h), b_{1}$ is the regression coefficient.

Additionally, $\lambda$ was defined as a function of $\mu_{\max }$ with respect to temperature using the Eq (8) (Robinson et al., 1998):

$$
\lambda=\frac{\mathrm{b}_{2}}{\mu_{\max }(T)}
$$

where $b_{2}$ is the regression coefficient, $\mu_{\max }(T)$ is the a function of temperature, which leads $\lambda$ to be defined as a function of storage temperature.

For the two-step and one-step modelling approaches, each of the parameters was calculated by means of NonLinearModel command which uses Levenberg Marquardt algorithm in the Matlab 8.3.0.532 (R2014a) software (MathWorks Inc., Natick, MA, USA). Determination of suitable starting values in nonlinear regression procedure is necessary step to estimate the accurate parameters. The starting values for the parameters, $y_{0}$ and $y_{\max }$ were selected as the minimum and maximum concentration of bacterial populations considering the entire temperature range, respectively. Randomly choosing starting points for the parameters, $b_{1}, b_{2}$ and $T_{0}$ might lead the estimated parameters to possible local optimal points around global one for especially the one-step modelling approach. Therefore, the starting points of these parameters were selected by using ga command which uses genetic algorithm in Global Optimization Toolbox of Matlab software for the twostep and one-step modelling approaches. Following successful iteration process for the nonlinear regression procedure, the global optimum values of the parameters were obtained.

\section{Comparison of the Goodness of Fit of the Models}

The comparison of the global models' estimation capabilities was performed by taking into consideration the root mean square error (RMSE) and the adjusted coefficient of 
determination (adjusted- $\mathrm{R}^{2}$ ) using Eqs. (9) and (10) respectively (Milkievicz et al. 2020):

$$
\begin{aligned}
& \text { RMSE }=\sqrt{\sum_{i=1}^{n} \frac{\left(\text { observed }_{i}-\text { fitted }_{i}\right)^{2}}{n-s}} \\
& \text { adjusted-R }{ }^{2}=1-\left(\frac{n-1}{n-s}\right)\left(\frac{S S E}{S S T}\right)
\end{aligned}
$$

where observed $\mathrm{d}_{\mathrm{i}}$ is the experimental bacterial growth, $n$ is the number of experiments, $\mathrm{s}$ is the number of parameters of the model, SSE is the sum of squares of errors and SST is the total sum of squares. RMSE and adjusted- $\mathrm{R}^{2}$ were calculated for entire data sets, which correspond to 5 for fish and 6 for pork and chicken meat considering observed and fitted values as $\log \mathrm{CFU} / \mathrm{g}$.

\section{Validation of the Global Model}

Verification of the developed models in the predictive food microbiology is crucial to be reliably employed as a simulation tool. The prediction performance of the global model that gave the best fitting capability to model the growth behaviour of Pseudomonas spp. existing in fish, pork and chicken microbiota were assessed by considering the growth data obtained from non-isothermal storage conditions. The comparison was done considering each of the global models' corresponding the bias $\left(\mathrm{B}_{\mathrm{f}}\right)$ and accuracy $\left(\mathrm{A}_{\mathrm{f}}\right)$ factors (Ross, 1996) given in Eqs. (11) and (12), respectively:

$$
\begin{aligned}
& \mathrm{B}_{\mathrm{f}}=10^{\frac{\sum_{\mathrm{i}=1}^{\mathrm{n}} \log \left(\mathrm{y}_{\text {predicted }} / \mathrm{y}_{\text {observed }}\right)}{\mathrm{n}}} \\
& \mathrm{A}_{\mathrm{f}}=10^{\frac{\sum_{\mathrm{i}=1}^{\mathrm{n}}\left|\log \left(\mathrm{y}_{\text {predicted }} / \mathrm{y}_{\text {observed }}\right)\right|}{\mathrm{n}}}
\end{aligned}
$$

where $y_{\text {predicted }}$ refers to predicted maximum growth rate (log $\mathrm{CFU} / \mathrm{h}$ ), yobserved refers to experimental maximum growth rate $(\log \mathrm{CFU} / \mathrm{h}), n$ refers to the number of data.

The $\mathrm{B}_{\mathrm{f}}$ is a measure of average variation between the predictions and observations. The model yielding $\mathrm{B}_{\mathrm{f}}$ greater than 1 is considered as 'fail dangerous', while the model providing $\mathrm{B}_{\mathrm{f}}$ less than 1 is considered as 'fail safe'. A value of 1 for $\mathrm{B}_{\mathrm{f}}$ indicates that there is a perfect agreement between the predictions and observations. The $\mathrm{A}_{\mathrm{f}}$ measures the average difference between the predictions and observations by disregarding whether the difference is positive or negative. The larger $\mathrm{A}_{\mathrm{f}}$ value, the less accurate is the average estimate (Ross,
1996). Additionally, two validation criteria known as mean deviation (MD) and mean absolute deviation (MAD) were calculated to evaluate the prediction capability of the models for non-isothermal storage conditions, as stated by Le Marc et al. (2008). A value of MD and MAD closing to 0 shows that the prediction capability of the model is perfect.

\section{Results and Discussion}

The growth data of the Pseudomonas spp. existing in fish, pork and chicken meat microbiota were fitted using two-step and one-step modelling approaches, and the statistical indicates were given in Table 1 . RMSE and adjusted- $\mathrm{R}^{2}$ values presented in Table 1 indicate the overall fitting capabilities for two-step modelling approach, which means that RMSE and adjusted- $\mathrm{R}^{2}$ values were calculated after consecutively done primary and secondary model fitting for entire data sets for each food product. The statistical indices showed that Huang model gave the best fitting performance for each food product. The fitting capability of the Baranyi model was the second. The Modified Gompertz and logistic models yielded almost the same fitting capabilities, which means that both of the primary models could not estimate the growth behaviour of Pseudomonas spp. as good as the Huang and Baranyi models estimated when the-wo step modelling approach was employed.

It is known that the degree of freedom while employing nonlinear regression procedure is important to decrease in uncertainty and increase in reliability of the model parameters (Huang, 2017). While doing simulation with one-step modelling approach, primary and secondary modelling is performed simultaneously considering whole experimental data set, which means that the simulation with one-step modelling approach has always higher degrees of freedom than the simulation with two-step modelling approach. Therefore, the improvement obtained from one-step modelling approach can be attributed to higher degrees of freedom in one-step modelling approach.

One-step modelling approach, an alternative way to traditionally used two-step modelling approach, was employed to quantitatively detect Pseudomonas spp. count. The statistical indices, RMSE and adjusted- $\mathrm{R}^{2}$ values, showing the fitting capability of one-step modelling approach were presented for each food product in Table 1 . The RMSE and adjusted- $\mathrm{R}^{2}$ values of each of the primary models and each food product based on one-step modelling approach were calculated maximum 0.466 and minimum 0.938 , respectively. These results showed that no matter which primary model was used, the one-step modelling approach gave considerably better prediction performance when the one-step modelling approach was employed. Therefore, the growth kinetics obtained from 
the one-step modelling approach for each food product (fish, pork and chicken meat) and each primary model (the modified Gompertz, logistic, Baranyi and Huang models) were given in Table 2.

The Huang model based on the one-step modelling approach showed that maximum counts of Pseudomonas spp. were 8.1 $\pm 0.1,9.5 \pm 0.1$ and $9.4 \pm 0.1$ for the fish, pork and chicken meat, respectively (Table 2 ), while the maximum counts were experimentally found to be of $8.30 \pm 0.30,9.8 \pm 0.2$ and 9.6 \pm 0.2 , for the fish, pork and chicken meat, respectively. This indicated that the Huang model provided suitable prediction performance for maximum counts of Pseudomonas spp. in each food product.

Table 1. Comparison of fitting capability of different primary models based on two-step and one-step modelling approaches

\begin{tabular}{|c|c|c|c|c|c|c|c|c|c|}
\hline \multirow{2}{*}{$\begin{array}{l}\text { Food prod- } \\
\text { ucts }\end{array}$} & \multirow{2}{*}{$\frac{\text { Primary models }}{\text { Modelling approach }}$} & \multicolumn{2}{|c|}{ Modified Gompertz } & \multicolumn{2}{|c|}{ Logistic } & \multicolumn{2}{|c|}{ Baranyi } & \multicolumn{2}{|c|}{ Huang } \\
\hline & & 2-step ${ }^{*}$ & 1-step & 2-step ${ }^{*}$ & 1-step & 2-step ${ }^{*}$ & 1-step & 2-step ${ }^{*}$ & 1-step \\
\hline \multirow{2}{*}{ Fish } & RMSE & 0.572 & 0.466 & 0.586 & 0.460 & 0.567 & 0.452 & 0.543 & 0.451 \\
\hline & Adjusted-R ${ }^{2}$ & 0.907 & 0.938 & 0.903 & 0.940 & 0.909 & 0.941 & 0.916 & 0.942 \\
\hline \multirow{2}{*}{ Pork } & RMSE & 0.609 & 0.383 & 0.506 & 0.406 & 0.607 & 0.440 & 0.573 & 0.430 \\
\hline & Adjusted-R ${ }^{2}$ & 0.941 & 0.977 & 0.959 & 0.974 & 0.941 & 0.969 & 0.948 & 0.971 \\
\hline \multirow{2}{*}{ Chicken } & RMSE & 0.540 & 0.260 & 0.423 & 0.263 & 0.389 & 0.259 & 0.397 & 0.256 \\
\hline & Adjusted-R ${ }^{2}$ & 0.933 & 0.984 & 0.959 & 0.984 & 0.965 & 0.984 & 0.964 & 0.985 \\
\hline
\end{tabular}

RMSE: root mean square error and Adjusted-R ${ }^{2}$ : adjusted coefficient of determination, calculated overall data sets for each food product considering observed and fitted values as $\log \mathrm{CFU} / \mathrm{g}$.

${ }^{*}$ RMSE and adjusted- $\mathrm{R}^{2}$ values calculated after consecutively done primary and secondary model fitting for entire data sets for each food product.

Table 2. Kinetic parameters of Pseudomonas spp. in different food products using one-step modelling approach.

\begin{tabular}{clllccc}
\hline \multirow{2}{*}{$\begin{array}{c}\text { Food } \\
\text { product }\end{array}$} & \multicolumn{1}{c}{ Primary models } & $y_{0}(\log \mathrm{CFU} / \mathrm{g})$ & $y_{\max }(\log \mathrm{CFU} / \mathrm{g})$ & $T_{0}\left({ }^{\circ} \mathrm{C}\right)$ & $b_{1}$ & $b_{2}$ \\
\cline { 2 - 7 } & Modified Gompertz & $3.4 \pm 0.2$ & $8.3 \pm 0.1$ & $-8.52 \pm 0.50$ & $0.0260 \pm 0.0014$ & $2.35 \pm 0.88$ \\
\multirow{3}{*}{ Fish } & Logistic & $2.9 \pm 0.3$ & $8.2 \pm 0.1$ & $-8.55 \pm 0.49$ & $0.0255 \pm 0.0014$ & $1.25 \pm 1.28$ \\
& Baranyi & $3.3 \pm 0.2$ & $8.1 \pm 0.1$ & $-8.58 \pm 0.46$ & $0.0238 \pm 0.0011$ & $1.41 \pm 0.69$ \\
& Huang & $3.4 \pm 0.1$ & $8.1 \pm 0.1$ & $-8.58 \pm 0.46$ & $0.0236 \pm 0.0010$ & $1.45 \pm 0.51$ \\
\cline { 2 - 7 } Pork & Modified Gompertz & $3.2 \pm 0.2$ & $9.8 \pm 0.2$ & $-14.30 \pm 1.25$ & $0.0179 \pm 0.0012$ & $2.65 \pm 1.04$ \\
& Logistic & $2.3 \pm 0.1$ & $9.7 \pm 0.2$ & $-14.28 \pm 1.30$ & $0.0173 \pm 0.0011$ & $0.00 \pm 0.00$ \\
& Baranyi & $3.3 \pm 0.2$ & $9.5 \pm 0.1$ & $-14.01 \pm 1.27$ & $0.0165 \pm 0.0012$ & $1.61 \pm 0.82$ \\
& Huang & $3.4 \pm 0.1$ & $9.5 \pm 0.1$ & $-14.03 \pm 1.24$ & $0.0165 \pm 0.0011$ & $1.78 \pm 0.64$ \\
\cline { 2 - 7 } Chicken & Modified Gompertz & $3.9 \pm 0.1$ & $9.8 \pm 0.2$ & $-7.77 \pm 0.37$ & $0.0289 \pm 0.0011$ & $2.55 \pm 0.65$ \\
& Logistic & $3.3 \pm 0.2$ & $9.6 \pm 0.1$ & $-7.76 \pm 0.37$ & $0.0284 \pm 0.0010$ & $1.14 \pm 0.96$ \\
& Baranyi & $3.9 \pm 0.1$ & $9.4 \pm 0.1$ & $-7.65 \pm 0.35$ & $0.0272 \pm 0.0009$ & $1.77 \pm 0.46$ \\
& Huang & $4.0 \pm 0.1$ & $9.4 \pm 0.1$ & $-7.62 \pm 0.35$ & $0.0270 \pm 0.0008$ & $1.74 \pm 0.36$ \\
\hline
\end{tabular}


While simulating the growth behaviour of microorganisms, accurately determining the exponential phase in which the growth rate reaches maximum value and the variations in organoleptic properties of foods also reach maxima and the lag phase in which organoleptic properties almost do not change are very important. $\mu_{\max }$ and $\lambda$ are the most important critical parameters to describe the growth behavior of microorganisms on food, and temperature has a key role in affecting directly both of these growth parameters (Huang, 2008). The kinetic parameters including $\mu_{\max }$ and $\lambda$ belonging to Pseudomonas spp. for each food product (fish, pork and chicken meat) and each primary model (the modified Gompertz, logistic, Baranyi and Huang models) were shown in Figure 1 and Figure 2, respectively. As it is expected, the figures demonstrate that $\mu_{\max }$ increased and $\lambda$ decreased because of rising storage temperature. At this point, it needs to be highlighted that the logistic model tented to yield $\lambda$ smaller than other primary models (modified Gompertz, Baranyi and Huang models) no matter for which food product was. Additionally, logistic model's statistical indices about $b_{2}$, which are used to calculate $\lambda$, were higher than other models for chicken and fish, which means a weakness of the logistic model about describing $\lambda$. These results are in a good agreement with the findings reported by Tarlak, (2020) for mushroom.

Validation is an important step to check how well the developed models are working. The Huang model is the best primary model simulating the growth behaviour of Pseudomonas spp. in fish, pork and chicken meat, therefore, Huang model was used to test the prediction capability for the Pseudomonas spp. concentration under non-isothermal storage conditions (Figure 3 ). The statistical values for validation of the Huang model are given in Table $3 . \mathrm{B}_{\mathrm{f}}$ and $\mathrm{A}_{\mathrm{f}}$ were calculated maximum 1.075 and 1.080 , respectively for all food products (fish, pork and chicken meat). $\mathrm{A} \mathrm{B}_{\mathrm{f}}$ and $\mathrm{A}_{\mathrm{f}}$ of 1 indicates no structural deviation of the model. The $\mathrm{B}_{\mathrm{f}}$ factor of 1.075 indicated that the model overestimates less than $7.5 \%$ whereas the $A_{f}$ factor of 1.080 showed that on average the predicted value was less than $8.0 \%$ different (either smaller or larger) from the observed value for each of the food products. In addition, MD and MAD values were less than 0.39 and 0.41 , respectively considering all food products (fish, pork and chicken meat). All these statistical indexes show that the Huang model can be reliably used to predict the growth behaviour of Pseudomonas spp. in fish, pork and chicken meat at not only isothermal but also non-isothermal storage conditions. Because the spoilage of fish, pork and chicken meat is directly linked with Pseudomonas spp. concentration, the one-step modelling approach could be also used for the prediction of product shelf life.
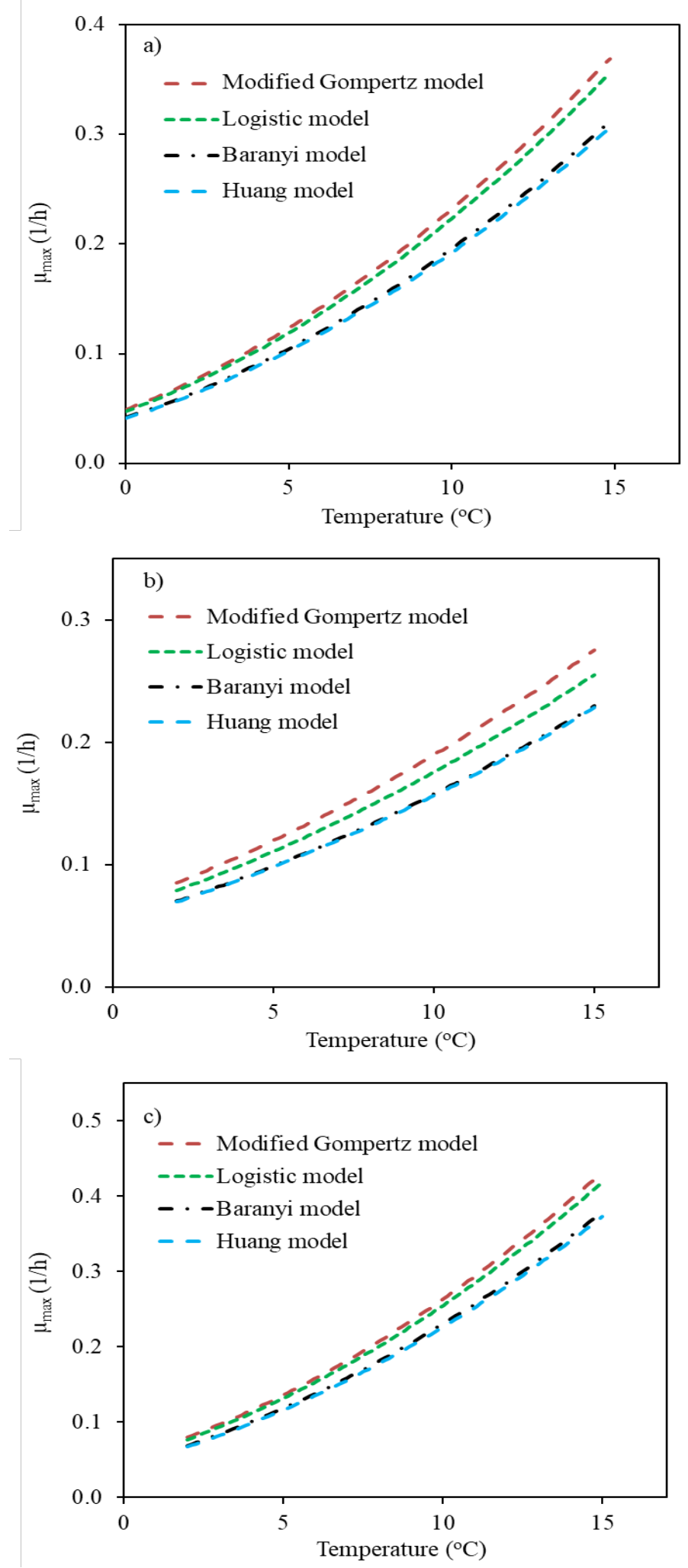

Figure 1. The effect of storage temperature on the maximum specific growth rate $\left(\mu_{\max }\right)$ values obtained from one-step modelling approach for (a) fish, (b) pork and (c) chicken meat. 

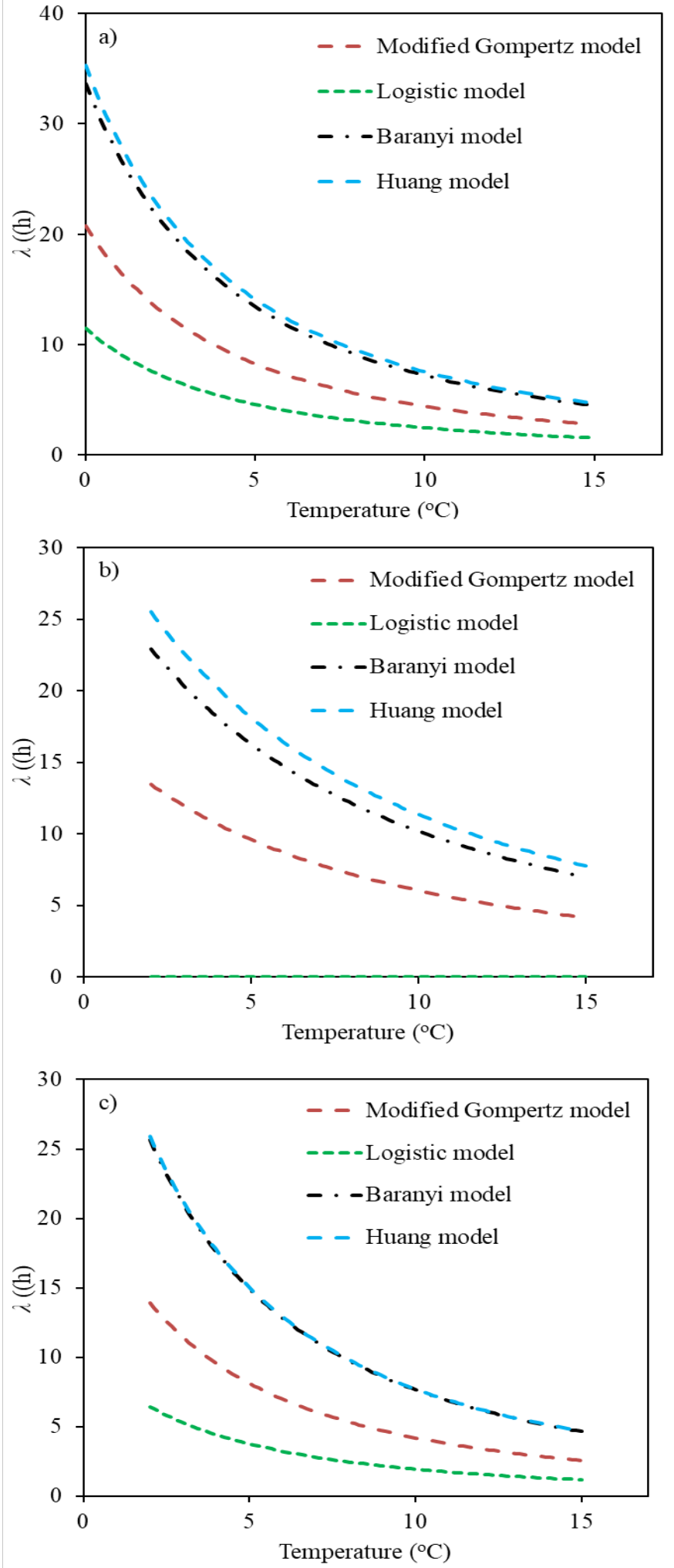

Figure 2. The effect of storage temperature on the lag phase duration $(\lambda)$ values obtained from one-step modelling approach for (a) fish, (b) pork and (c) chicken meat.
Table 3. Validation criteria of one-step modelling approach based on the Huang model.

\begin{tabular}{ccccc}
\hline $\begin{array}{c}\text { Food } \\
\text { products }\end{array}$ & $\mathrm{B}_{\mathrm{f}}$ & $\mathrm{A}_{\mathrm{f}}$ & $\mathrm{MD}$ & $\mathrm{MAD}$ \\
\hline Fish & 1.014 & 1.059 & 0.02 & 0.33 \\
Pork & 1.075 & 1.080 & 0.39 & 0.41 \\
Chicken & 1.016 & 1.047 & 0.18 & 0.31 \\
\hline
\end{tabular}
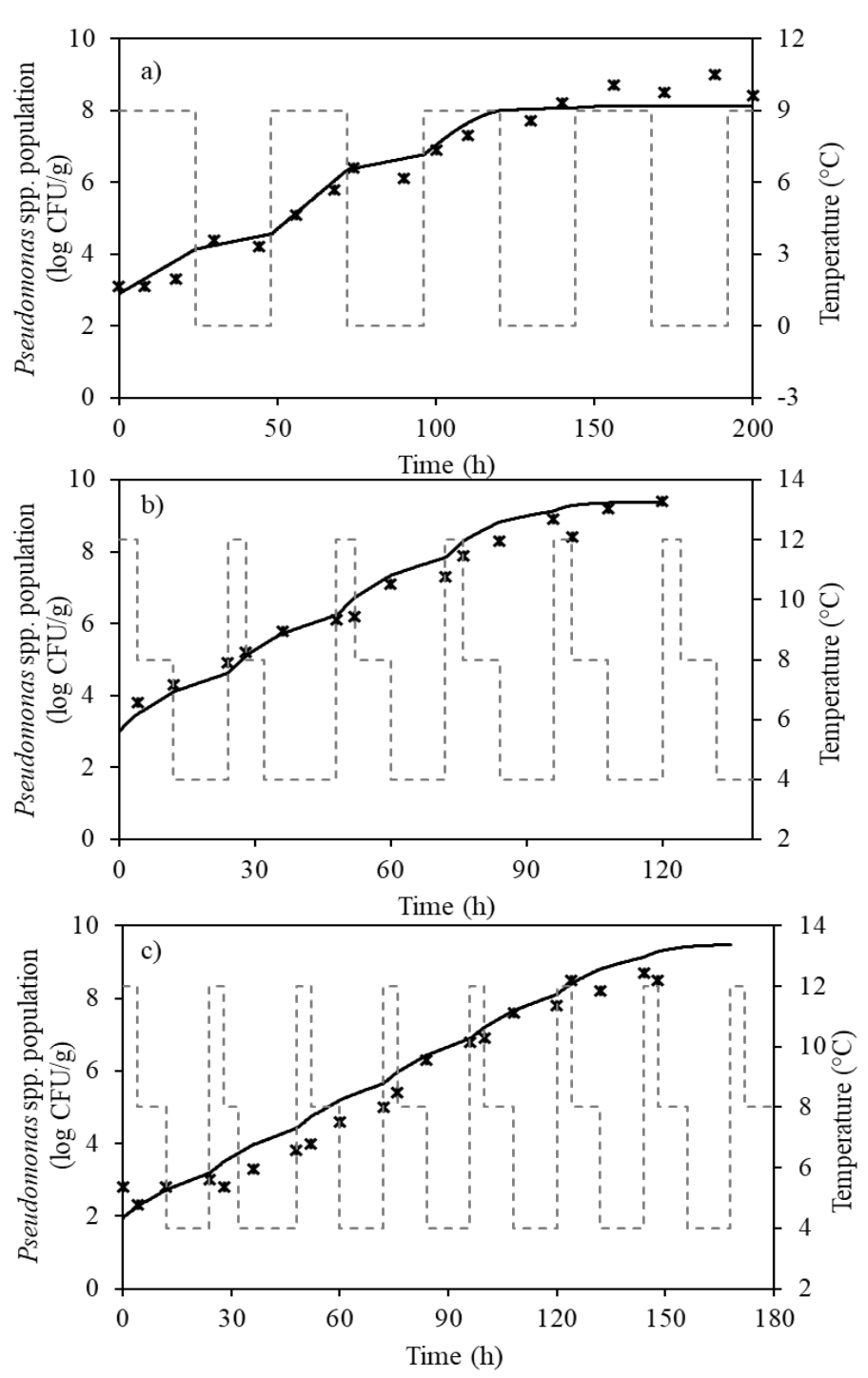

Figure 3. The prediction of Pseudomonas spp. concentration in (a) fish, (b) pork and (c) chicken meat subjected to non-isothermal storage conditions. Observed (*) and predicted (-) Pseudomonas spp. concentration. The dashed lines (--) show the changing temperature during storage. 


\section{Conclusion}

No matter which primary model was used, the one-step modelling approach considerably improved the prediction capability of the models, which were published for the quantitative prediction of Pseudomonas spp. concentration in aerobically stored fish, pork and chicken meat. The successfully validated differential form of the Huang model merged with the Ratkowsky model provided valuable information to evaluate and simulate the growth behaviour of the Pseudomonas spp. in aerobically stored fish, pork and chicken meat under non-isothermal conditions in which the food products are usually subjected to during storage, delivery and retail marketing. The predictive models used in this work have a high potential to be used as a simulation tool for the meat processors to follow the microbiological quality of the food products before they reach to the consumers.

\section{Compliance with Ethical Standard}

Conflict of interests: The authors declare that for this article they have no actual, potential or perceived the conflict of interests.

Ethics committee approval: Author declare that this study does not include any experiments with human or animal subjects.

Funding disclosure: This work was financially supported by Istanbul Gedik University through the centre supporting Scientific Research Projects.

Acknowledgments: Dr. Fatih Tarlak would like to thank Asst. Prof. Dr. Emel Birol for her help during this research.

Disclosure: -

\section{References}

Baranyi, J., Roberts, T.A. (1994). A dynamic approach to predicting bacterial growth in food. International Journal of Food Microbiology, 23, 277-294.

https://doi.org/10.1016/0168-1605(94)90157-0

Bovill, R.A., Bew, J., Baranyi, J. (2001). Measurements and predictions of growth for Listeria monocytogenes and Salmonella during fluctuating temperature: II. Rapidly changing temperatures. International Journal of Food Microbiology, 67, 131-137.

https://doi.org/10.1016/S0168-1605(01)00446-9

Bruckner, S. (2010). Predictive shelf life model for the improvement of quality management in meat chains. PhD thesis.
Bruckner, S., Albrecht, A., Petersen, B., Kreyenschmidt, J. (2013). A predictive shelf life model as a tool for the improvement of quality management in pork and poultry chains. Food control, 29, 451-460..

https://doi.org/10.1016/j.foodcont.2012.05.048

Buchanan, R.L., Whiting, R.C., Damert, W.C. (1997). When is simple good enough: a comparison of the Gompertz, Baranyi, and three-phase linear models for fitting bacterial growth curves. Food Microbioogy, 14, 313-326.

https://doi.org/10.1006/fmic.1997.0125

Dominguez, S.A., Schaffner, D.W. (2007). Development and validation of a mathematical model to describe the growth of Pseudomonas spp. in raw poultry stored under aerobic conditions. International Journal of Food Microbiology, 120, 287-295.

https://doi.org/10.1016/j.ijfoodmicro.2007.09.005

Ghollasi-Mood, F., Mohsenzadeh, M., Hoseindokht, M.R., Varidi, M. (2017). Quality changes of air-packaged chicken meat stored under different temperature conditions and mathematical modelling for predicting the microbial growth and shelf life. Journal Food Safety, 37, e12331. https://doi.org/10.1111/jfs.12331

Huang, L. (2008). Growth kinetics of Listeria monocytogenes in broth and beef frankfurters Determination of lag phase duration and exponential growth rate under isothermal conditions. Journal of Food Science, 73, e235-242.

https://doi.org/10.1111/j.1750-3841.2008.00785.x

Huang, L. (2017). IPMP Global Fit-A one-step direct data analysis tool for predictive microbiology. International Journal of Food Microbiology, 262, 38-48.

https://doi.org/10.1016/j.ijfoodmicro.2017.09.010

Jewell, K. (2012). Comparison of 1-step and 2-step methods of fitting microbiological models. International Journal of Food Microbiology, 160, 145-161.

https://doi.org/10.1016/j.ijfoodmicro.2012.09.017

Koutsoumanis, K. (2001). Predictive modeling of the shelf life of fish under nonisothermal conditions. Applied and Environmental Microbiology, 67, 1821-1829.

https://doi.org/10.1128/AEM.67.4.1821-1829.2001

Le Marc, M., Plowman, J., Aldus, C. F., Munoz-Cuevas, M., Baranyi, J., Peck, M.W. (2008). Modelling the growth of Clostridium perfringens during the cooling of bulk meat. International Journal of Food Microbiology, 128, 41-50. 


\section{https://doi.org/10.1016/j.ijfoodmicro.2008.07.015}

Lytou, A., Panagou, E.Z., Nychas, G.J.E. (2016). Development of a predictive model for the growth kinetics of aerobic microbial population on pomegranate marinated chicken breast fillets under isothermal and dynamic temperature conditions. Food Microbioogy, 55, 25-31.

https://doi.org/10.1016/j.fm.2015.11.009

Martino, K.G., Marks, B.P. (2007). Comparing uncertainty resulting from two-step and global regression procedures applied to microbial growth models. Journal of Food Protection, 70, 2811-2818.

https://doi.org/10.4315/0362-028X-70.12.2811

Milkievicz, T., Badia, V., Souza, V. B., Longhi, D. A., Galvão, A. C., da Silva Robazza, W. (2020). Development of a general model to describe Salmonella spp. growth in chicken meat subjected to different temperature profiles. Food Control, 112, 107151.

https://doi.org/10.1016/j.foodcont.2020.107151

Pérez-Rodríguez, F., Valero, A. (2013). Predictive Microbiology in Foods. Springer, New York. ISBN: 978-1-4614$5520-2$

https://doi.org/10.1007/978-1-4614-5520-2

Ratkowsky, D.A., Olley, J., McMeekin, T.A., Ball, A. (1982). Relationship between temperature and growth rate of bacterial cultures. Journal of Bacterioogy, 149, 1-5.

https://doi.org/10.1128/JB.149.1.1-5.1982
Robinson, T.P., Ocio, M.J., Kaloti, A., Mackey, B.M. (1998). The effect of the growth environment on the lag phase of Listeria monocytogenes. International Journal of Food Microbiology, 44, 83-92.

https://doi.org/10.1016/S0168-1605(98)00120-2

Ross, T. (1996). Indices for performance evaluation of predictive models in food microbiology. Journal of Applied Bacterioogy, 81, 501-508.

https://doi.org/10.1111/j.1365-2672.1996.tb03539.x

Tarlak, F. (2020). Development and validation of one-step modelling approach for prediction of mushroom spoilage. Journal of Food and Nutrition Research, 59(4), 281-289.

Whiting, R.C. (1995). Microbial modeling in foods. Critical Reviews in Food Science and Nutrition, 35, 467-494.

https://doi.org/10.1080/10408399509527711

Zwietering, M. H., De Wit, J. C., Cuppers, H. G. A. M., van't Riet, K. (1994). Modeling of bacterial growth with shifts in temperature. Applied and Environmental Microbiology, 60, 204-213.

https://doi.org/10.1128/AEM.60.1.204-213.1994

Zwietering, M.H, Jongenburger, I., Rombouts, F.M, van't iet, K. (1990). Modeling of the bacterial growth curve. Applied and Environmental Microbiology, (56), 1875-1881. https://doi.org/10.1128/AEM.56.6.1875-1881.1990 